\title{
Decreased expression of carbonic anhydrase isozyme II, rather than of isozyme VI, in submandibular glands in long-term zinc-deficient rats
}

\author{
Tomoko Goto $^{1,2}$, Hitoshi Shirakawa ${ }^{1}$, Yuji Furukawa ${ }^{1}$ and Michio Komai ${ }^{1}{ }^{*}$ \\ ${ }^{1}$ Laboratory of Nutrition, Graduate School of Agricultural Science, Tohoku University, 1-1 Tsutsumidori-Amamiyamachi, Aoba-ku, \\ Sendai 981-8555, Japan \\ ${ }^{2}$ Department of Biotechnology, School of Science and Engineering, Ishinomaki Senshu University, 1 Shinmito, Minamisakai, \\ Ishinomaki 986-8580, Japan
}

(Received 3 January 2007 - Revised 12 June 2007 - Accepted 25 June 2007)

We previously reported that in rats, long-term Zn deficiency significantly reduced taste sensitivity and total carbonic anhydrase (CA) activity in the submandibular gland. We therefore investigated the effects of Zn deficiency on salivary secretion and the expressions of CA isozymes (II and VI) in the rat submandibular gland, since those isozymes are thought to be related to taste sensation and salivary secretion. Male Sprague-Dawley rats, age 4 weeks, were divided into three groups (Zn-def, low-Zn and pair-fed, that were fed a diet containing $2 \cdot 2,4 \cdot 1$ or $33.7 \mathrm{mg} \mathrm{Zn/kg,} \mathrm{respectively,}$ for $42 \mathrm{~d}$ ). Northern blot analysis indicated that Zn deficiency reduced CA II mRNA expression in the submandibular gland without reducing CA VI mRNA expression. In Western blot analysis, Zn deficiency significantly reduced CA II (erythrocyte CA) protein expression in the submandibular gland without reducing CA VI protein expression. Salivary secretion was lower in the Zn-def group than in the pair-fed group. These results suggest that decreased CA isozyme II expression underlies the decreased CA activity previously reported in the submandibular gland in Zn-def rats, and this may reduce regular salivary secretion.

Zinc deficiency: Carbonic anhydrase II and VI: Submandibular glands

Carbonic anhydrase (CA; EC 4.2.1.1), a Zn metalloenzyme that catalyses the reversible hydration of carbon dioxide, participates in $\mathrm{pH}$ regulation, and in the transport of fluid and ions in a wide range of species and tissues ${ }^{1-3}$. The CA present in salivary glands and saliva are thought to participate in ion transport, secretory processes and saliva production, and also in the regulation of the $\mathrm{pH}$ and buffering capacity of the saliva $^{4,5}$. Moreover, CA appears to be involved in gustation because hypogeusia has been reported as a side effect by patients undergoing acetazolamide therapy ${ }^{6}$. A decade ago, Komai \& Bryant $^{7}$ showed that the perception of carbonated water (via the lingual trigeminal nerve) by rats requires the participation of CA. Moreover, they showed that MK-927, which is a membrane-permeable type of CA inhibitor, inhibits the responses of the chorda tympani nerve to carbonated water, quinine hydrochloride and L-glutamic acid solution when applied topically to the tongue surface in rats $^{8}$. Later, others found that CA inhibitors alter the perception of carbonated water in rats?

It is well known that $\mathrm{Zn}$ deficiency leads to hypogeusia (decreased taste acuity) in both man and rats, a symptom that can be reversed by the administration of $\mathrm{Zn}$. We recently confirmed that long-term $\mathrm{Zn}$ deficiency significantly reduced taste sensitivity at the level of the chorda tympani nerve in rats ${ }^{10}$. Since we had already demonstrated that long-term $\mathrm{Zn}$ deficiency significantly reduces CA activity in the submandibular gland and taste epithelium ${ }^{11}$, we hypothesised that the decreased taste sensitivity seen in long-term $\mathrm{Zn}$-def rats is a consequence of a reduction in total salivary CA activity. Since it was not clear which CA isozymes might be involved in this decrease in total CA activity, we performed the present study to examine the effects of $\mathrm{Zn}$ deficiency on the expressions of individual CA isozymes (mRNA and protein) in the rat submandibular gland. Our decision as to which isozymes to study was informed by the following background.

To date, at least eleven isozymes of CA and CA-related proteins have been identified in mammals $\mathrm{s}^{2,3,12,13}$. Some are expressed in almost all tissues, while others are tissue or organ specific. Four are cytosolic isozymes (I, II, III and VII), four are membrane bound (IV, IX, XII and XIV), two are present in mitochondria (VA and $\mathrm{VB}$ ) and one is a secretory isozyme (VI). Although they all belong to the same $\alpha$-class of $\mathrm{CA}^{14}$, the isozymes show considerable divergence in DNA sequence, chromosome location and enzymic properties $^{12,15}$. Erythrocyte CA (I and II) and VI are the ones usually reported to be expressed in salivary glands ${ }^{5,16-21}$, although some studies have found an expression of CA III or IV in these glands ${ }^{22-24}$. Parkkila et al. ${ }^{16}$ could find no staining specific for CA I in the serous acinar cells in human parotid and submandibular glands, while Ogawa

Abbreviations: CA, carbonic anhydrase; OD, optical density; Tris, tri(hydroxymethyl)-aminomethane.

* Corresponding author: Dr Michio Komai, fax +81 22717 8813, email mkomai@biochem.tohoku.ac.jp 
et $a l .{ }^{19}$ could detect no obvious differences in parenchymal staining between sections stained with polyclonal rabbit antirat erythrocyte CA (CA I and CA II) antibody and those stained with monoclonal anti-rat CA II antibody. Cytosolic CA II has a high catalytic efficiency and is widely expressed in mammalian organs. CA I has a lower catalytic efficiency than CA II and is expressed primarily in blood cells ${ }^{3}$. CA VI, the only secretory isozyme highly expressed in salivary glands, is expressed in the serous acinar cells of the parotid and submandibular glands, from where it is secreted into the saliva. For the above reasons, we focused on the expressions of CA II (erythrocyte CA: CA I and CA II) and CA VI (mRNA and protein) in the rat submandibular gland in our attempt to clarify the part played by $\mathrm{Zn}$ in the CA-related maintenance of taste sensation and saliva secretion.

Our other purpose was to investigate salivary secretion in $\mathrm{Zn}$-def rats. Kondo et al. ${ }^{25}$ reported that $\mathrm{Zn}$ constitutes an important factor in the production of secretory granules in the cells of the granular convoluted tubules in the submandibular gland. Likewise, Ishii et al. ${ }^{26}$ suggested that in the submandibular gland, $\mathrm{Zn}$ (together with many Zn-dependent enzymes) is closely involved in the production and degranulation of secretory granules in the glandular epithelial cells, and also in the contraction of the myoepithelial cells. However, little is known about salivary secretion in Zn-def rats. The outer surface of mammalian taste receptor cells is normally covered with saliva, suggesting that the salivary environment plays an important role in the initial events of gustation. For that reason, we also examined the effects of $\mathrm{Zn}$ deficiency on salivary secretion rate.

\section{Materials and methods}

\section{Animals and diets}

Male Sprague-Dawley rats (age 4 weeks; weight $80-90 \mathrm{~g}$ at the time of delivery to our laboratory) were purchased from Japan SLC (Hamamatsu, Japan). They were fed a commercial pellet diet (F-2; Funabashi Farms Ltd, Funabashi, Japan) for $3 \mathrm{~d}$ before being started on the experimental diet, and they were then divided into three groups: severe $\mathrm{Zn}$-def (Zn-def), marginal Zn-def (low-Zn) and pair-fed. All rats were maintained on a $12 \mathrm{~h}$ light-dark cycle at $22 \pm 1^{\circ} \mathrm{C}$ with a constant humidity of $50 \pm 10 \%$. The experimental design of the study was approved by the Animal Research-Animal Care Committee of the Graduate School of Agricultural Science, Tohoku University. The entire experiment closely followed the guidelines issued by that committee, which strictly follows government legislation in Japan (1980). Moreover, the care and use of the rats involved in the present study were under the surveillance of the above-mentioned committee.

The compositions of the basal experimental diets have been described previously ${ }^{10}$. Since dietary $\mathrm{Zn}$ levels at 2-4 mg Zn/ $\mathrm{kg}$ diet are classified as marginal Zn deficiency ${ }^{27}$, we set the following three types of diets with different $\mathrm{Zn}$ levels. The added amounts of $\mathrm{Zn}$ in each diet of the $\mathrm{Zn}$-def, marginal $\mathrm{Zn}$-def (low-Zn) and Zn-sufficient were 0, 3.84 and $33.8 \mathrm{mg} /$ $\mathrm{kg}$ diet, respectively, while the amounts of $\mathrm{Zn}$ in each diet analysed by atomic absorption spectrophotometry (SAS-727; SEIKO Denshikogyo, Tokyo, Japan) were $2 \cdot 2,4 \cdot 1$ and $33.7 \mathrm{mg} \mathrm{Zn} / \mathrm{kg}$ diet, respectively. Harper's mineral commercial mixture (Oriental Yeast, Tokyo, Japan) was used to provide the mineral mixture for the low- $\mathrm{Zn}$ diet because we have found that by feeding a diet containing this mixture, we can create a subclinical $\mathrm{Zn}$ deficiency in rats (although overt signs and symptoms of $\mathrm{Zn}$ deficiency do not appear, plasma $\mathrm{Zn}$ levels are reduced ${ }^{11}$ ). In fact, Harper's mineral mixture contains $0.2 \mathrm{~g} \mathrm{ZnCl}_{2} / \mathrm{kg}$ mixture ${ }^{28}$ (added amount of $\mathrm{Zn}$, $3.84 \mathrm{mg} / \mathrm{kg}$ diet), a level well under the recommended dietary requirement in the AIN-93 diet $\left(1.65 \mathrm{~g} \mathrm{ZnCO}_{3} / \mathrm{kg}\right.$ mixture). Dietary intake levels below $12 \mathrm{mg} \mathrm{Zn/kg} \mathrm{diet} \mathrm{should} \mathrm{be} \mathrm{con-}$ sidered $\mathrm{Zn}$ deficient ${ }^{29}$. The mineral mixture for the $\mathrm{Zn}$-def diet was prepared using the same components as in Harper's mixture but with $\mathrm{ZnCl}_{2}$ excluded completely (added amount of $\mathrm{Zn}, 0 \mathrm{mg} / \mathrm{kg}$ diet). The mixture for the $\mathrm{Zn}$-sufficient diet was prepared by supplementing the commercial Harper's mixture with $1.6 \mathrm{~g} \mathrm{ZnCl}_{2} / \mathrm{kg}$ (added amount of $\mathrm{Zn}, 33.8 \mathrm{mg} / \mathrm{kg}$ diet), and this diet provides an adequate amount of $\mathrm{Zn}$ for rats $^{30}$.

The $\mathrm{Zn}$-def and low-Zn rats were given free access to the appropriate diet, but the pair-fed rats, which were fed the Zn-sufficient diet, were pair-fed against the $\mathrm{Zn}$-def rats $(1 \mathrm{~d} \text { later })^{10}$. After feeding on the experimental diet for $42 \mathrm{~d}$, the rats were killed under anaesthesia (ethyl ether inhalation), then deprived of blood. The submandibular gland was immediately excised from twelve rats (Zn-def, $n 4$; low-Zn, $n 4$; pair-fed, $n 4$ ) and frozen in liquid $\mathrm{N}_{2}$. In order to evaluate the mRNA and protein expression levels for CA II and CA VI in the submandibular gland on day 42 of the experimental period, Northern and Western blot analyses were performed.

\section{Ribonucleic acid extraction}

Total RNA was isolated from the submandibular gland using ISOGEN (Nippon Gene Co. Ltd, Tokyo, Japan) according to the manufacturer's protocol. One part of frozen tissue $(80-100 \mathrm{mg})$ was immediately homogenised in $1 \mathrm{ml}$ ISOGEN. The RNA in the samples was quantified using optical density (OD) 260 and the quality of the mRNA samples was assessed using the OD260:OD280 ratio.

\section{Cloning of rat carbonic anhydrase II and carbonic anhydrase VI $c D N A$}

First-strand cDNA was synthesised from the total RNA isolated from the rat submandibular gland using SuperScript II RNase $\mathrm{H}^{-} \mathrm{RT}$ (Invitrogen, Cergy Pontoise, France). The amplification of rat CA VI cDNA was carried out using TaKaRa Taq DNA polymerase (Takara Biomedicals, Kyoto, Japan). The primers were referred to the nucleotide sequence of expressed sequence tag (EST) clone estimated mouse CA VI (GenBank accession no. AF079835: forward, TAAGGAATGTGG; reverse, TGAAAATCTCCAAAATCACTTTA). A PCR product of approximately $380 \mathrm{bp}$ was separated by agarose-gel electrophoresis, isolated using Gene Clean (Qbiogene, Irvine, CA, USA), ligated into the pT7blue T plasmid vector (Novagen Inc, Madison, WI, USA) and transformed using Escherichia coli DH5 $\alpha$. The nucleotide sequences of the CA VI cDNA inserts in the plasmid vector and EST clone containing CA II cDNA (GenBank accession no. AW524377) were determined using a sequencing kit (Applied Biosystems, Foster City, CA, USA). The cDNA 
fragments for the hybridisation probe were prepared from both plasmids digested with Eco RI and HindIII.

\section{Northern blot analysis}

Total RNA, $25 \mu \mathrm{g}$, from the submandibular gland was electrophoresed through $1.2 \%$ agarose gel containing formaldehyde $(2.2 \mathrm{~mol} / \mathrm{l})$. After the electrophoresis, the RNA were transferred to Hybond- $\mathrm{N}^{+}$nylon membranes (Amersham Biotech, Little Chalfont, Bucks, UK), and immobilised by UV crosslinking. The membrane was prehybridised at $68^{\circ} \mathrm{C}$ for $30 \mathrm{~min}$ in ExpressHyb hybridisation solution (Clontech Laboratories Inc., Palo Alto, CA, USA). Rat CA II and CA VI cDNA fragments were labelled with $\left[{ }^{32} \mathrm{P}\right] \mathrm{dCTP}$ using a Random Primer DNA Labelling Kit (Takara Biomedicals, Kyoto, Japan). The labelled DNA probes were purified by gel filtration, and hybridised to the membranes at $68^{\circ} \mathrm{C}$ for 90 min in ExpressHyb hybridisation solution. After hybridisation, the membranes were washed twice for $30 \mathrm{~min}$ at $50^{\circ} \mathrm{C}$ in $2 \times$ saline sodium citrate (SSC), $0.05 \%$ SDS, and twice for $40 \mathrm{~min}$ at $50^{\circ} \mathrm{C}$ in $0.1 \times \mathrm{SSC}, 0.1 \% \mathrm{SDS}$. The membranes were then exposed to an imaging plate (Fujifilm, Tokyo, Japan) for image detection. Signal intensity on the imaging plate was quantified using FLA-2000 (Fujifilm, Tokyo, Japan) and analysed using Image Reader VI 4J and Image Gauge version 3.0 software (Fujifilm, Tokyo, Japan). Quantitative analyses of CA II and CA VI mRNA level were normalised with respect to the abundance of $18 \mathrm{~S}$ rRNA.

\section{Western blot analysis}

One part of the submandibular gland $(200-300 \mathrm{mg}$ ) was immediately homogenised in six parts by volume of cold tri(hydroxymethyl)-aminomethane (Tris)- $\mathrm{HCl}$ buffer $(50 \mathrm{~mm}$; $\mathrm{pH}$ 7.2). Each homogenate was centrifuged at $1000 \mathrm{~g}$ for $15 \mathrm{~min}\left(4^{\circ} \mathrm{C}\right)$, then the supernatant fraction was used for Western blot analysis. Protein concentration was measured by the method of Lowry et $a l .{ }^{31}$. Protein $(10 \mu \mathrm{g})$ was loaded on to a $12.5 \%$ polyacrylamide gel, then transferred to an ImmobilonPPVDF membrane (Millipore Japan, Tokyo, Japan) for $2 \mathrm{~h}$ at $250 \mathrm{~mA}$ using transfer buffer containing $48 \mathrm{~mm}$-Tris- $\mathrm{HCl}$, 39 mM-glycin and $10 \%$ methanol. The blot was washed three times in Tris-buffered saline Tween 20 (TBS-T) buffer (20 mm-Tris-HCl, pH7.6, $137 \mathrm{~mm}-\mathrm{NaCl}, 0.1 \%$ Tween 20). The membrane was then blocked with $10 \%$ skimmed milk powder (Snow Brand, Tokyo, Japan) in TBS-T buffer for $1 \mathrm{~h}$ at room temperature. After blocking, the membrane was incubated in the presence of the primary antibodies for CA II and CA VI for $1 \mathrm{~h}$ at room temperature. The primary antibodies used were as follows: (1) polyclonal rabbit anti-rat erythrocyte CA (CA I and CA II) antibody (1:5000) and (2) monoclonal mouse anti-rat CA VI antibody (1:5000). Both antibodies were generous gifts from Dr Yuzo Ogawa (Osaka University, Osaka, Japan). The membrane was then washed and incubated with the secondary antibody. The secondary antibodies used were as follows: (1) anti-rabbit IgG conjugated to horseradish peroxidase (1:5000; Pierce Chemical

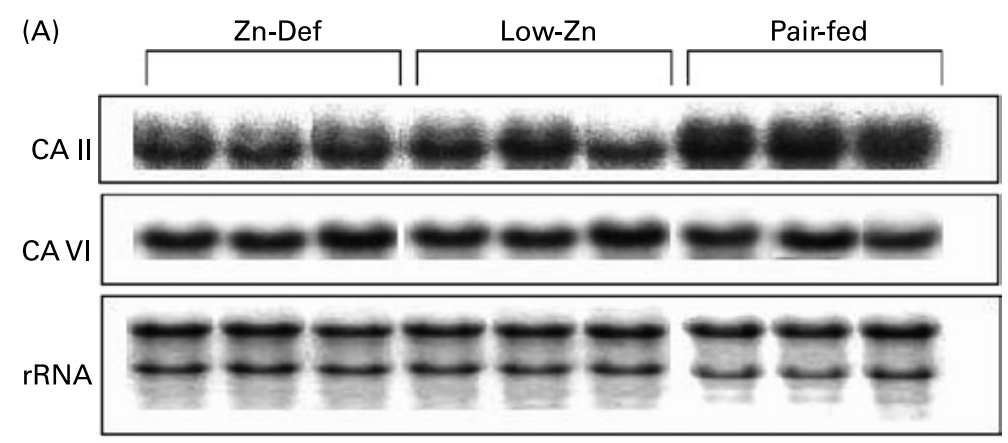

(B)

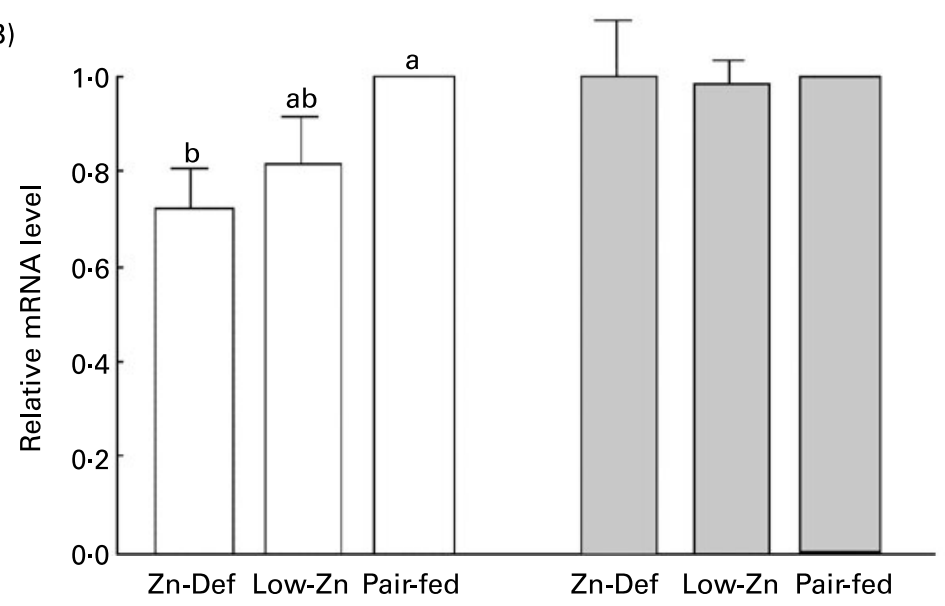

Fig. 1. Northern blot analysis for measurement of the expressions of carbonic anhydrase (CA) II and CA VI mRNA in rat submandibular glands on day 42 of the experimental period. (A) Total RNA isolated from $\mathrm{Zn}$-def, marginally $\mathrm{Zn}$-def (low- $\mathrm{Zn}$ ) and pair-fed rats was loaded in the various lanes, with the corresponding rRNA being used as the control. (B) mRNA levels for CA II ( $\square$ ) and CA VI ( $\square$ ) are shown relative to those in pair-fed rats. Values are means ( $n$ 4), with their standard errors represented by vertical bars. ${ }^{\text {ab }}$ Mean values with unlike letters were significantly different $(P<0.05)$. 
Company, Rockford, IL, USA) and (2) anti-mouse IgG conjugated to horseradish peroxidase (1:5000; Amersham Biotech). The immune complexes were detected with the aid of ECL + Plus Western blotting detection reagents (Amersham Biotech) using the manufacturer's protocol. The bands were visualised by an enhanced chemiluminescence method. The intensity of the bands was quantified using LAS-2000 (Fujifilm, Tokyo, Japan) and analysed using Image Reader VI 4J and Image Gauge version 3.0 software (Fujifilm).

\section{Measurement of salivary secretion rate}

An additional twelve rats (Zn-def, $n 4$; low-Zn, $n 4$; pair-fed, $n 4$ ) were used after they had been fed the experimental diets for $42 \mathrm{~d}$. They were anaesthetised with urethane $(100 \mathrm{mg} / \mathrm{kg}$ body weight) plus $\alpha$-chloralose ( $50 \mathrm{mg} / \mathrm{kg}$ body weight) at $3 \mathrm{~h}$ after the end of feeding, and the trachea was cannulated to facilitate breathing. The whole saliva was collected for 1 min using absorbent cotton wool (a small cotton bud), the weight of each bud being measured before and after collection.

\section{Statistical analysis}

The results are expressed as mean values with their standard errors. All data were analysed using a one-way ANOVA.
In all experiments, post hoc multiple comparisons were made using the Bonferroni-Dunn test. The StatView program (StatView J-4.5; Abacus Concepts, Berkeley, CA, USA) was used for the analysis in each case.

\section{Results and discussion}

Our $\mathrm{Zn}$-def rats displayed features typical of $\mathrm{Zn}$ deficiency, as described both by other investigators and in our previous work $^{11}$. Anorexia and growth retardation, as well as a depletion of the plasma (serum) $\mathrm{Zn}$ concentration, were observed. After $21 \mathrm{~d}$ feeding on the Zn-def diet, severe signs of $\mathrm{Zn}$ deficiency were evident (epilation, hyperkeratosis of oral mucosal tissues and scaly encrustation of the paws). In contrast, none of these severe signs was seen in the low$\mathrm{Zn}$ or pair-fed rats. Plasma $\mathrm{Zn}$ concentrations of the $\mathrm{Zn}$-def rats were significantly reduced compared with the pair-fed rats after $4 \mathrm{~d}$ feeding. In the case of the low-Zn rats, none of these severe signs was seen, although plasma $\mathrm{Zn}$ levels were reduced (data not shown).

Northern blot analysis was performed to examine the effects of Zn deficiency on the abundance of the mRNA for CA II and CA VI (Fig. 1). The CA II mRNA expression in the submandibular gland was lower in the $\mathrm{Zn}$-def rats than in the pair-fed rats, and it was at an intermediate level in the low-Zn rats (Fig. 1 (B)).

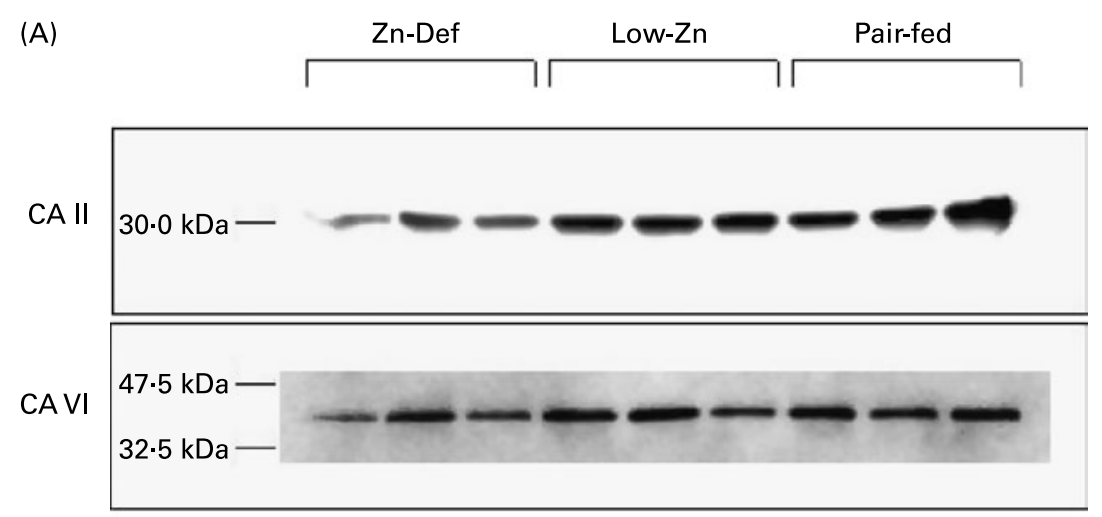

(B)

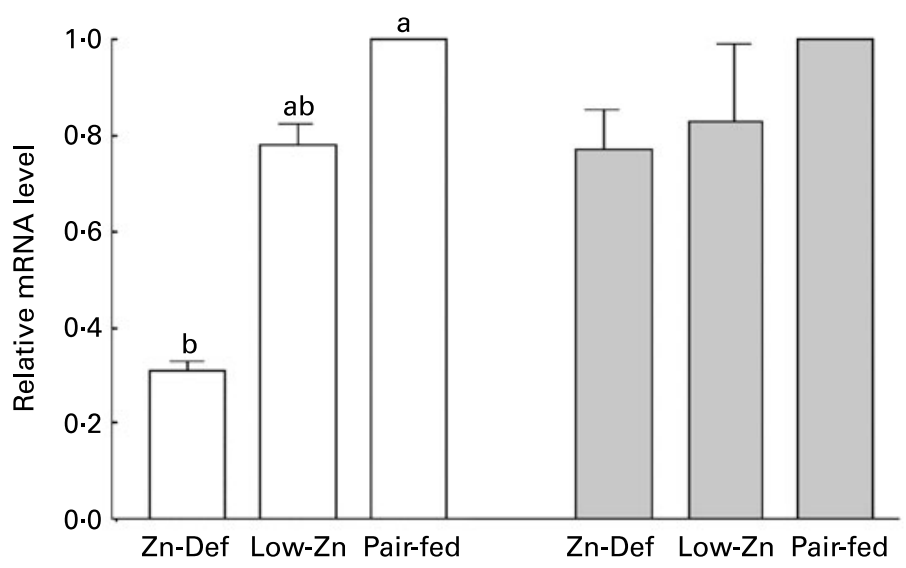

Fig. 2. Western blot analysis for measurement of the expressions of carbonic anhydrase (CA) II and CA VI in rat submandibular glands from Zn-def, marginally Zn-def (low-Zn) and pair-fed rats on day 42 of the experimental period. (A) CA II was detected using polyclonal rabbit anti-rat erythrocyte CA (CA I and CA II) antibody, while CA VI was detected using monoclonal mouse anti-rat CA VI antibody. (B) Amounts of CA II ( $\square$ ) and CA VI ( $\square$ ) expressed relative to those in pair-fed rats. Values are means $(n 3)$, with their standard errors represented by vertical bars. ${ }^{\text {ab }}$ Mean values with unlike letters were significantly different $(P<0.05)$. 
The relative level of CA II mRNA (normalised with respect to rRNA) was 0.72 (SEM 0.09) in the Zn-def rats $(P=0.031 v$. that in the pair-fed rats), while that in the low-Zn rats was 0.81 (SEM 0.11) $(P=0 \cdot 137)$. On the other hand, CA VI mRNA expression in both the $\mathrm{Zn}$-def and low- $\mathrm{Zn}$ rats was at the same level as in the pair-fed rats.

The reactions of the primary antibodies in the Western blot analysis are illustrated in Fig. 2 (A). No obvious differences in parenchymal staining are reportedly seen between those sections stained with polyclonal rabbit anti-rat erythrocyte CA (CA I and CA II) antibody and those stained with monoclonal anti-rat CA II antibody ${ }^{17,19}$. On this basis, we assumed that the reaction of the polyclonal antibody to CA I plus CA II indicated the reaction to $\mathrm{CA}$ II. The antibodies we used have been shown to respond to the corresponding rat CA II and $\mathrm{CA} \mathrm{VI}{ }^{19}$. Although Hennigar et al. $^{5}$ have demonstrated CA I and/or CA II immunoreactivity in the serous acinar cells of several rodent species, including the rat, it is necessary to take into consideration the cross-reaction of their anti-human antibodies with other isozymes in these animals ${ }^{17}$. In the present study, CA II protein expression in the submandibular gland was significantly lower in the Zn-def rats than in the pair-fed rats, and it was at an intermediate level in the low$\mathrm{Zn}$ rats (Fig. 2 (B)). The relative amount of CA II protein in the Zn-def rats was 0.31 (SEM 0.02) $(P=0.011 v$. that in the pair-fed rats), while that in the low-Zn rats was 0.78 (SEM 0.04) $(P=0 \cdot 280)$. This confirmed that CA II (erythrocyte CA) protein expression was affected by dietary $\mathrm{Zn}$ content. On the other hand, CA VI protein expression in both the $\mathrm{Zn}$-def and low-Zn rats was at the same level as in the pairfed rats.

As an overall tendency, the results indicated that $\mathrm{Zn}$ deficiency leads to a clear reduction both in mRNA abundance and in protein level of CAII, but not in CA VI. This seems to indicate the complexity of the effects of $\mathrm{Zn}$ deficiency in transcriptional and translational regulation of gene expression. However, at this point, we do not know how $\mathrm{Zn}$ deficiency affected differently in these two isozymes.

In our previous report ${ }^{11}$, CA activity in the submandibular gland of the Zn-def rats was $36.4 \%$ of that shown by the pair-fed rats, while that of the low-Zn rats was $66.3 \%$ of the level shown by the pair-fed rats. The reduction in CA activity

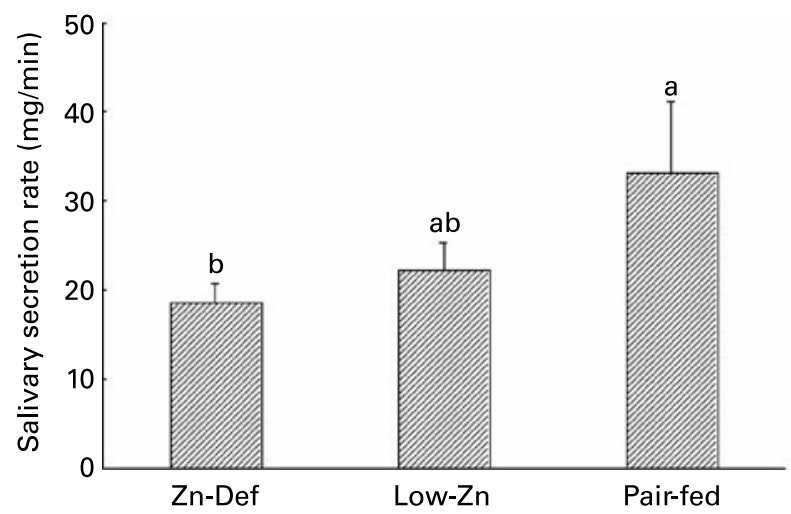

Fig. 3. Salivary secretion rate in Zn-def, marginally Zn-def (low-Zn) and pairfed rats on day 42 of the experimental period. Values are means $(n 4)$, with their standard errors represented by vertical bars. ${ }^{a b}$ Mean values with unlike letters were significantly different $(P<0.05)$. in the submandibular gland seems to correspond to the level of the reduction in CA II protein expression. These results suggest that a reduction in CA II expression may underlie the reduction in total CA activity previously reported in the submandibular gland in Zn-def rats ${ }^{11}$.

Fig. 3 shows that the salivary secretion rate was lower in the Zn-def rats (18.53 (SEM 2.19) $\mathrm{mg} / \mathrm{min})$ than in the pair-fed rats (33.18 (SEM 8.12$) \mathrm{mg} / \mathrm{min})(P=0.046)$ after $42 \mathrm{~d}$ feeding, and that it was at an intermediate level in the low-Zn rats $(22.23$ (SEM 3.05) $\mathrm{mg} / \mathrm{min}$ ). The salivary secretion rate of the Zn-def rats was $55.8 \%$ of that shown by the pair-fed rats, while that of the low-Zn rats was $67.0 \%$ of the level shown by the pair-fed rats. This confirmed that salivary secretion rate is affected by the dietary $\mathrm{Zn}$ content.

Thus in the present study we detected a reduction in CA II expression in the submandibular gland in Zn-def rats, although CA VI expression was not reduced. Since cytosolic CA II has been proposed both to catalyse the production of salivary bicarbonate $e^{16}$ and to play a role in transacinar water movement $^{32}$, a reduction in CA II expression in the submandibular gland in $\mathrm{Zn}$-def rats seems to be in accord with the decreased salivary secretion observed in such rats. Consideration of the experimental data presented here leads us to suppose that CA II might need to be present if a sufficient amount of saliva is to be produced. It has been reported that CA VI secretion occurs independently of salivary secretion in human subjects ${ }^{33}$, although it is not clear whether or not CA VI is involved in salivary secretion.

In summary, in the present investigation we confirmed that $\mathrm{Zn}$ deficiency reduces CA II (protein and mRNA) expression in the rat submandibular gland without a reduction in CA VI expression (protein or mRNA). These results suggest that a decreased CA II expression (a) underlies the decreased total $\mathrm{CA}$ activity seen in the submandibular gland in $\mathrm{Zn}$-def rats, and (b) may reduce regular salivary secretion and also reduce taste sensitivity.

\section{Acknowledgements}

We gratefully acknowledge Dr Yuzo Ogawa (Osaka University, Japan) for the generous gift of antibodies. We are grateful to Dr Y. Obara (Tohoku University, Japan) and Dr B. P. Bryant (Monnel Chemical Senses Center, PA, USA) for kind advice. We thank Mr Satoru Horigome (Tohoku University, Japan) for the preparation of cDNA probes. The present study was supported in part by grants from the Japan Society for the Promotion of Science for Young Scientists (11-2-401325 ) for T. G., and by the Grant-in-Aid for Scientific Research (B) (2) (15380087) for M. K.

\section{References}

1. Maren TH (1967) Carbonic anhydrase: chemistry, physiology, and inhibition. Physiol Rev 47, 595-781.

2. Tashian RE (1989) The carbonic anhydrases: widening perspectives on their evolution, expression and function. Bioessays 10, $186-192$.

3. Sly WS \& Hu PY (1995) Human carbonic anhydrases and carbonic anhydrase deficiencies. Annu Rev Biochem 64, 375-401.

4. Blair-West JR, Fernley RT, Nelson JF, Wintour EM \& Wright RD (1980) The effect of carbonic anhydrase inhibitors on the 
anionic composition of sheep's parotid saliva. J Physiol 299, $29-44$.

5. Hennigar RA, Schulte BA \& Spicer SS (1983) Immunolocalization of carbonic anhydrase isozymes in rat and mouse salivary and exorbital lacrimal glands. Anat Rec 207, 605-614.

6. Miller LG \& Miller SM (1990) Altered taste secondary to acetazolamide therapy. J Fam Pract 31, 199-200.

7. Komai M \& Bryant BP (1993) Acetazolamide specifically inhibits lingual trigeminal nerve responses to carbon dioxide. Brain Res 612, 122-129.

8. Komai M, Bryant BP, Takeda T, Suzuki H \& Kimura S (1994) The effect of topical treatment with a carbonic anhydrase inhibitor, MK-927, on the response of the chorda tympani nerve to carbonated water. In Olfaction and Taste XI, pp. 22 [K Kurihara, N Suzuki and H Ogawa, editors]. Tokyo: Springer-Verlag Tokyo.

9. Simons CT, Dessirier JM, Carstens MI, O'Mahony M \& Carstens E (1999) Neurobiological and psychophysical mechanisms underlying the oral sensation produced by carbonated water. J Neurosci 19, 8134-8144.

10. Goto T, Komai M, Suzuki H \& Furukawa Y (2001) Long-term zinc deficiency decreases taste sensitivity in rats. $J$ Nutr 131, 305-310.

11. Goto T, Komai M, Bryant BP \& Furukawa Y (2000) Reduction in carbonic anhydrase activity in the tongue epithelium and submandibular gland in zinc-deficient rats. Int J Vitam Nutr Res $\mathbf{7 0}$ $110-118$

12. Fujikawa-Adachi K, Nishimori I, Taguchi T \& Onishi S (1999) Human mitochondrial carbonic anhydrase VB. cDNA cloning, mRNA expression, subcellular localization, and mapping to chromosome X. J Biol Chem 274, 21228-21233.

13. Mori K, Ogawa Y, Ebihara K, et al. (1999) Isolation and characterization of CA XIV, a novel membrane-bound carbonic anhydrase from mouse kidney. J Biol Chem 274, 15701-15705.

14. Lindskog S (1997) Structure and mechanism of carbonic anhydrase. Pharmacol Ther 74, 1-20.

15. Hewett-Emmett D \& Tashian RE (1996) Functional diversity, conservation, and convergence in the evolution of the $\alpha-, \beta-, \gamma-$ carbonic anhydrase gene families. Mol Phylogenet Evol 5, 50-77.

16. Parkkila S, Kaunisto K, Rajaniemi L, Kumpulainen T, Jokinen K \& Rajaniemi H (1990) Immunohistochemical localization of carbonic anhydrase isoenzymes VI, II, and I in human parotid and submandibular glands. J Histochem Cytochem 38, 941-947.

17. Ogawa Y, Chang C-K, Kuwahara H, Hong S-S, Toyosawa S \& Yagi $T$ (1992) Immunoelectron microscopy of carbonic anhydrase isozyme VI in rat submandibular gland: comparison with isozymes I and II. J Histochem Cytochem 40, 807-817.

18. Ogawa Y, Hong S-S, Toyosawa S, Kuwahara H, Shimazaki M \& Yagi T (1993) Immunoelectron microscopy of carbonic anhydrase isozyme VI in human submandibular gland: comparison with isozymes I and II. J Histochem Cytochem 41, 343-351.

19. Ogawa Y, Fernley RT, Ito R \& Ijuhin N (1998) Immunohistochemistry of carbonic anhydrase isozymes VI and II during development of the rat salivary glands. Histochem Cell Biol 110, 81-88.

20. Peagler FD, Redman RS, McNutt RL, Kruse DH \& Johansson I (1998) Enzyme histochemical and immunohistochemical localization of carbonic anhydrase as a marker of ductal differentiation in the developing rat parotid gland. Anat Rec 250, 190-198.

21. Redman RS, Peagler FD \& Johansson I (2000) Immunohistochemical localization of carbonic anhydrase I, II, and VI in the developing rat sublingual and submandibular glands. Anat Rec 258, 269-276.

22. Spicer SS, Ge Z-H, Tashian RE, Hazen-Martin DJ \& Schulte BA (1990) Comparative distribution of carbonic anhydrase isozymes III and II in rodent tissues. Am J Anat 187, 55-64.

23. Asari M, Igarashi S-I, Sasaki K, Amasaki T, Nishita T \& Amasaki H (1991) Immunocytochemical localization of the carbonic anhydrase III in the rat parotid gland. J Anat 179, $9-14$.

24. Fujikawa-Adachi K, Nishimori I, Sakamoto S, Morita M, Onishi S, Yonezawa S \& Hollingsworth MA (1999) Identification of carbonic anhydrase IV and VI mRNA expression in human pancreas and salivary glands. Pancreas 18, 329-335.

25. Kondo I, Ozono S, Sato K \& Ito Y (1989) Histology of the submandibular gland in experimentally induced zinc-deficient mice. Bull Kanagawa Dent Coll 17, 159-163.

26. Ishii K, Sato M, Akita M \& Tomita H (1999) Localization of zinc in the rat submandibular gland and the effect of its deficiency on salivary secretion. Ann Otol Rhinol Laryngol 108, 300-308.

27. Reeves PG (1996) AIN-93 purified diets for the study of trace element metabolism in rodents. In Trace Elements in Laboratory Rodents, pp. 3-37 [RR Watson and I Wolinsky, editors]. New York: CRC Press Inc.

28. Harper AE (1959) Amino acid balance and imbalance. I. Dietary level of protein and amino imbalance. J Nutr 68, 405-418.

29. National Research Council Subcommittee on Laboratory Animal Nutrition (1995) Nutrient Requirements of Laboratory Animals, pp. 11-79. Washington, DC: National Academy of Sciences.

30. Reeves PG, Nielsen FH \& Fahey GC Jr (1993) AIN-93 purified diets for laboratory rodents: final report of the American Institute of Nutrition Ad Hoc Writing Committee on the reformulation of the AIN-76A rodent diet. J Nutr 123, 1939-1951.

31. Lowry OH, Rosebrough NJ, Farr AL \& Randall RJ (1951) Protein measurement with the Folin phenol reagent. J Biol Chem 193, 265-275.

32. Nauntofte B (1992) Regulation of electrolyte and fluid secretion in salivary acinar cells. Am J Physiol 263, G823-G837.

33. Parkkila S, Parkkila A-K \& Rajaniemi H (1995) Circadian periodicity in salivary carbonic anhydrase VI concentration. Acta Physiol Scand 154, 205-211. 